\title{
Targeted Expression of GLI1 in the Salivary Glands Results in an Altered Differentiation Program and
} Hyperplasia

\author{
Marie Fiaschi, ${ }^{*}$ Åsa Kolterud, ${ }^{*}$ Mats Nilsson, ${ }^{*}$ \\ Rune Toftgård, ${ }^{*}$ and Björn Rozell ${ }^{\dagger}$ \\ From the Center for Biosciences, Department of Biosciences and \\ Nutrition," and Department of Laboratory Medicine, ${ }^{\dagger}$ Karolinska \\ Institutet, Huddinge, Sweden
}

Hedgehog (Hh) signaling is a regulator of salivary gland morphogenesis, but its role in postnatal glands has only recently begun to be addressed. To examine the effects of deregulated $\mathrm{Hh}$ signaling in the salivary gland, we expressed the Hh effector protein GLI1, in salivary epithelial cells using both cytokeratin 5 and mouse mammary tumor virus (MMTV) transgenic systems. Ectopic pathway activation resulted in restrained acinar differentiation, formation of cystic lesions, and prominent appearance of ductal structures. Moreover, induced expression of GLI1 aids the formation of hyperplastic lesions, which closely resemble GLI1-induced changes in murine skin and mammary glands, suggesting that GLI1 targets cells with similar characteristics in different tissues. Furthermore, GLI1-expressing salivary epithelial cells are actively dividing, and GLI1-induced lesions are proliferative, an incident accompanied by enhanced expression of the Hh target genes, cyclin D1, and Snail. GLI1-induced salivary lesions regress after transgene withdrawal and become histologically normalized. Taken together, our data reveal the ability of GLI1 to modulate salivary acinar differentiation and to promote proliferation of ductal epithelial cells. (Am J Pathol 2011, 179:2569-2579; DOI: 10.1016/j.ajpath.2011.07.033)

Although other exocrine organs such as the mammary glands, pancreas, and prostate have received intense interest from developmental as well as tumorigenic points of view, far less is known about these processes in the salivary glands. The salivary glands are divided into three major types: parotid (PG), submandibular (SMG), and sublingual (SLG) glands. ${ }^{1}$ In addition to these, there are a number of minor intraoral types. Although the three pairs of major salivary glands have distinct histological structures and functions in the adult, their embryonic development by branching morphogenesis share common mechanisms, as reviewed elsewhere. ${ }^{1-3}$ The SMG is the most studied gland and in the mouse, its development begins on embryonic day 11 (E 11), as a thickening of the epithelium ventral to the tongue, a stage known as the pre bud stage. Next, during the initial bud stage, the thickening extends into the underlying neural-crest derived mesenchyme and form the initial SMG bud. ${ }^{4}$ The solid cord of epithelium elongates and grows by repeated end-bud branching into the mesenchyme to produce a bush-like structure, pseudoglandular stage. During the canalicular stage, ducts develop lumens and the first sign of acinar differentiation becomes evident. Peripheral cells in the ducts are actively dividing while those at the center of the presumptive lumens undergoe apoptosis. During the final stage, the terminal end bud stage, well-developed lumens are evident in the terminal end buds and the presumptive ducts. Ductal development is completed at E18 while acinar differentiation continues postnatally with final differentiation at puberty. The fully developed gland mainly consists of secretory acini. The acini are organized into lobules and are drained, via a ductal system comprising intercalated, striated and excretory ducts, into the oral cavity.

The Hedgehog $(\mathrm{Hh})$ signaling cascade mediates critical developmental steps in the formation of appendages, including hair, teeth, and the salivary glands. ${ }^{5,6}$ The first indication that $\mathrm{Hh}$ signaling actively takes part in salivary gland

Supported by grants from the Swedish Cancer Society, Swedish Research Council, NIH Program Project Grant AR47898, and NIH/National Cancer Institute Mouse Models of Human Cancers Consortium Grant U01 CA105491.

Accepted for publication July 19, 2011

Supplemental material for this article can be found at http://ajp. amjapthol.org or at doi: 10.1016/j.ajpath.2011.07.033

Current address of B.R., Department of Veterinary Disease Biology, Faculty of Life Sciences, University of Copenhagen, Frederiksberg, Denmark.

Address reprint requests to Björn Rozell, Ph.D., Department of Veterinary Disease Biology, Faculty of Life Sciences, University of Copenhagen, Ridbanevej 3, 1870 Frederiksberg C, Denmark. E-mail: brozell@life.ku.dk. 
morphogenesis came from gene targeting studies of the sonic hedgehog Shh gene. ${ }^{7}$ In these Shh-null mice, which die just before birth, submandibular gland development stops at the pseudoglandular stage, before canalization and lumen formation. ${ }^{6}$ Furthermore, treatment of E14 SMGs with the Hh inhibitor cyclopamine, decreases both branching and cell proliferation. ${ }^{6}$ In contrast, treatment of embryonic mouse SMG rudiments with Shh peptide promotes the formation of acinus-like structures with a lumen. ${ }^{8}$ Several of the $\mathrm{Hh}$ signaling components eg, Shh, Ptch1, Smo, Gli1, and Gli3 are present throughout embryonic submandibular development, further supporting an active role for the $\mathrm{Hh}$ pathway in salivary gland histogenesis. ${ }^{6}$

So far, scant information is available on $\mathrm{Hh}$ signaling in postnatal or adult salivary glands. A recent study did however suggest that $\mathrm{Hh}$ is involved in salivary gland regeneration. ${ }^{9}$ When proliferation of salivary gland progenitor/stem cells was induced using the so-called ligation technique, ${ }^{10}$ the Wnt signaling pathway and several components of the Hh pathway, including Gli1 and Ptch1, were induced. ${ }^{9} \mathrm{Hh}$ signaling is also critical for regeneration of several other organs such as stomach and exocrine pancreas. ${ }^{11,12}$ In several of the tissues in which $\mathrm{Hh}$ is involved in renewal, pathway mis-activation has been linked to tumor formation. A similar role for $\mathrm{Hh}$ signaling in the development of salivary gland cancer has, so far, not been investigated.

To examine directly the in vivo consequence of an altered Hh signaling pathway in the salivary glands, we have taken advantage of the fact that the mouse mammary tumor virus LTR (MMTV-LTR) promoter, not only directs expression in the mammary gland, but is also highly active in salivary glands and other organs. ${ }^{13}$ Using the MMTV promoter to drive expression of a doxycyclineactivated transactivator protein (tTA) in combination with a target allele, we conditionally expressed the Hh effector GLI1. The results are compared with those in another murine model in which constitutive expression of GLI1 is directed by the bovine keratin 5 promoter. Salivary glands with induced GLI1 expression, independent of the promoter used, reveal severe morphological defects comprising hyperplastic lesions, reduced number of acini, cystic lesions and prominent ductal structures. The appearance of hyperplastic lesions, are concurrent with induced GLI1 expression, and these changes adopt a prominent basaloid feature. Further, these cells are actively dividing and display and express the $\mathrm{Hh}$ target genes, Cyclin D1and Snail. Withdrawal of transgene induction normalizes to some extent the salivary gland appearance. These observations reveal striking in vivo consequences of ectopic GLI1 expression on salivary gland morphology.

\section{Materials and Methods}

\section{Transgenic Mice and Genotyping}

Mice expressing the GLI1 oncogene by the inducible MMTV (MMTV-GLI1) or the constitutively active K5 (K5GLI1) promoter have been described previously ${ }^{14}$ and ${ }^{15}$ respectively. Doxycycline $(2 \mathrm{mg} / \mathrm{mL})$ and $5 \%$ sucrose, was added to the drinking water with start either during the mating of TREGLI1 to MMTVrtTA mice or at the time of weaning, and continued until the animal was sacrificed if not stated otherwise. The MMTV-GLI1 mice were bred to hemizygosity for both the transactivator and the transgene. Organs and tissues were dissected from wild-type (wt) and MMTVGLI1 virgin (5-10 weeks), 6- to 33-week-old parous, and long-term-treated (46-50 weeks) parous female and male mice. Mice expressing GLI1 under the K5 promoter were sacrificed between the age of 4 weeks and 6 months. All mice were generated and bred within an SPF barrier facility. The experimental conditions were approved by the Stockholm South Animal Ethics Committee.

\section{RT-PCR Analysis}

RNA was isolated using RNAzolB (RNABee, TEL-TEST, Friendswood, TX) and random hexamer-primed complementary DNA (CDNA) was generated using the reverse transcription system (Promega, Madison, WI). Gli1, Ptch1, rtTA, and actin mRNA levels were determined in the MMTV-GLI1 salivary glands while Gli1 and $\beta$-actin mRNA levels were determined in the K5-GLI1 salivary glands essentially as described elsewhere. ${ }^{14,15}$ All experiments were independently repeated at least three times and no amplification was obtained without reverse transcription (data not shown).

\section{Histological Analysis and Immunohistochemistry}

Tissues were fixed overnight in either neutral buffered $4 \%$ paraformaldehyde or Feketes fixative, paraffin embedded, sectioned, and stained with hematoxylin/eosin (H\&E). Immunohistochemistry, immunofluorescence labeling and periodic acid-Schiff staining of diastasetreated sections (PASD) staining were performed essentially as described in. ${ }^{14,16}$ Primary antibodies: rabbit polyclonal anti-GLI1 (Cell signaling, Danvers, MA) 1:1000 used for immunofluorescence labeling, rabbit polyclonal anti-Ptch1 generated using the C-terminal 18 aa as antigen (custom made by Research Genetics, Huntsville, AL) 1:200, rabbit polyclonal anti-Keratin 6 (Babco, Richmond, CA) 1:2000, rabbit polyclonal anti-Keratin 5 (Babco) 1:4000, rabbit polyclonal anti-Keratin 1 (Babco) 1:1000, rabbit polyclonal anti-Loricrin (Babco) 1:1000, rabbit polyclonal anti-Keratin 14 (Babco) 1:2500, rabbit polyclonal anti-AQP5 (Alpha Diagnostics, San Antonio,TX) 1:200, rabbit polyclonal anti-Snail (Abcam, Cambridge, UK) 1:800 and rabbit polyclonal anti-Cyclin D1 (Thermo Fisher Scientific Inc, Fremont, CA) 1:100. The rabbit polyclonal antibody Nkcc1 1:1000, the rabbit polyclonal antibody recognizing Keratin 17 1:2500 and the rat polyclonal antibody Keratin 8 1:100 were obtained from Dr. Jim Turner, Dr. Pierre Coulombe (John Hopkins University School of Medicine, Baltimore, MD) and Dr. Igor Mikaelian (Jackson Laboratory, Bar Harbor, ME), respectively. Detection of BrdU (1:25, BD Biosciences, Franklin Lakes, NJ), smooth muscle actin (SMA) (1:50, Novocastra), p63, 4A4 (1:200, Santa Cruz Biotechnology, Santa Cruz, CA), $\beta$-catenin (1:5000, BD Biosciences), and 
E-cadherin (1:2000, BD Biosciences) was performed using mouse monoclonal antibodies and the Histomouse kit (Zymed Laboratories, Carlsbad, CA), according to the manufacturer's instructions. The cell permeable DNA-interactive agent Draq5 (Biostatus Limited, Shepshed, UK) was used for nuclear staining of immunofluorescencelabeled salivary gland sections. As negative controls, all experiments were performed without the primary antibody in the presence of equal concentrations of normal rabbit, goat or mouse IgG. The number of GLI1 and BrdU positive salivary epithelial cells were quantified in GLI1 expressing SLG, SMG and PG from animals sacrificed at 1 year of age. A total of 1000 nuclei from three separate areas in three samples were counted and data presented as a percentage.

\section{Results}

To analyze the effect of deregulated Hh signaling pathway in the salivary glands, two different transgenic mouse models were used. In the first model the reverse tet-responsive transactivator (rtTA) was expressed under the control of the MMTV promoter and the TRE-linked Hh effector GLI1 was activated by administration of doxycycline in the drinking water. GLI1 expression was induced, in both males and females, either continuously from mating (MMTV-GLI1-prenatal) or starting at 3 weeks of age (MMTV-GLI1-3w) and sometimes continued for up to 1 year (MMTV-GLI1-long-term). Because activation of the MMTV promoter has been reported to be up-regulated by hormones during pregnancy and lactation, ${ }^{17}$ most female mice (including control mice) were allowed to undergo several rounds of pregnancy (multiparous). In the second transgenic model, constitutive expression of GLI1 was under the control of the bovine K5 promoter.

\section{Morphological Defects in the MMTV-GLI1-Expressing Salivary Glands}

Histological analysis of wild-type (wt) and MMTV-GLI1 salivary glands revealed striking consequences of ectopic GLI1 expression. In contrast to the normal salivary architecture seen in wt glands (Figure 1, A-C) the MMTVGLI1 salivary glands displayed two major changes; areas comprised of small aggregates of basaloid cells with an outer layer of more palisaded cells (Figure 1, D-J), and ectatic (ie, distended) ducts (Figure 1, E, H, and I), sometimes with mucous luminal plugs (Figure $1 \mathrm{E}$, asterisk). The ductal changes were accompanied by accumulation of basaloid cellular aggregates peripheral to the luminal cells [Figure 1, E, H (arrows), I and J]. Cells in these hyperplastic areas presented a homogenous phenotype, with high expression of the basal markers p63, cytokeratins 5 (K5), 14 (K14), and 17 (K17) and low/absent expression of the luminal marker cytokeratin 8 (K8) and myoepithelial marker smooth muscle actin (SMA) (Figure 2A). Furthermore, most of the GLI1 induced hyperplastic lesions stained positive for cytokeratin 6 (K6), which is normally low/absent in wt salivary epithelial cells (Figure
2A; see also Supplemental Figure $\mathrm{S} 1$ at $h t t p: / / a j p$. amjpathol.org). A proportion of the K6 positive ductal cells co-expressed p63, whereas $\mathrm{K} 5$ and $\mathrm{K} 8$ were expressed in different cell populations (see Supplemental Figure S1 at http://ajp.amjpathol.org). Both basaloid aggregates and ductal lesions appeared in salivary glands of all of the parous GLI1-expressing females (Figure 1, D, E, and G-J) as well as in long-term doxycycline treated males (Figure 1F). Squamous metaplasia with keratinization was occasionally seen (Figure 1E, arrow; see also Supplemental Figure S2 at http://ajp.amjpathol.org). These lesions stained positive for squamous ( $\mathrm{K} 1$ and Loricrin), basal (p63 and K5) and luminal (K8) epithelial markers as well as K6 and GLI1. No positive staining was observed, however, using another myoepithelial marker (SMA) (see Supplemental Figure S2 at $h$ ttp://ajp.amjpathol.org). Furthermore, in the MMTV-GLI1-long-term cohort, dense collagenous matrix deposition was found to be associated with the above-described morphological changes (Figure $1 \mathrm{~F}$, asterisk). Although the changes in the different salivary glands were extensive, we were unable to detect overt tumor formation. The wt salivary glands showed a normal immunohistological profile when stained with p63, K5, K14, K17, K8, and SMA (Figure 2A; see also Supplemental Figure $\mathrm{S} 1$ at $h$ ttp://ajp.amjpathol.org).

\section{Initiation Time and Duration of Transactivator Expression Determine the Severity of Salivary Gland Defects}

The severity of the observed salivary gland changes varied with onset and duration of GLI1 induction. Also the parous state of female mice had an effect, as no obvious changes could be detected in virgin mice. When GLI1 expression was induced 3 weeks after birth (MMTVGLI1-3w), a milder phenotype was observed, changes developed slower and were less widespread (Figure 1, G and J). In contrast, animals in which GLI1 expression was activated during their prenatal development (MMTVGLI1-prenatal) showed extensive changes (Figure 1, $\mathrm{D}-\mathrm{F}, \mathrm{H}$, and I). This was particularly evident in the SLG, where hardly any normal parenchyma remained (Figure 11). In addition, long-term activation (>1 year) of GLI1 expression (MMTV-GLI1-long-term), led to extensive changes in all parous female (Figure $1, D$ and $H$ ) and male salivary glands (Figure 1F). The occurrence of salivary gland changes in long-term induced males suggests that similar changes would occur also in virgin female mice on long-term GLI1 activation. RT-PCR and immunohistochemical analysis revealed that a high percentage of the salivary epithelial cells in the MMTV-GLI1prenatal (Figure 2B) and MMTV-GLI1-long-term (Figure 2C) female mice expressed GLI1, whereas morphologically normal salivary epithelial cells did not (Figure 2B; see also Supplemental Figure S1B at http://ajp.amjpathol.org). Quantification demonstrated that $35.2 \% \pm 3.1 \%$ of the SLG, $21.2 \% \pm 3.8 \%$ of the SMG, and $18.7 \% \pm 3.1 \%$ of 

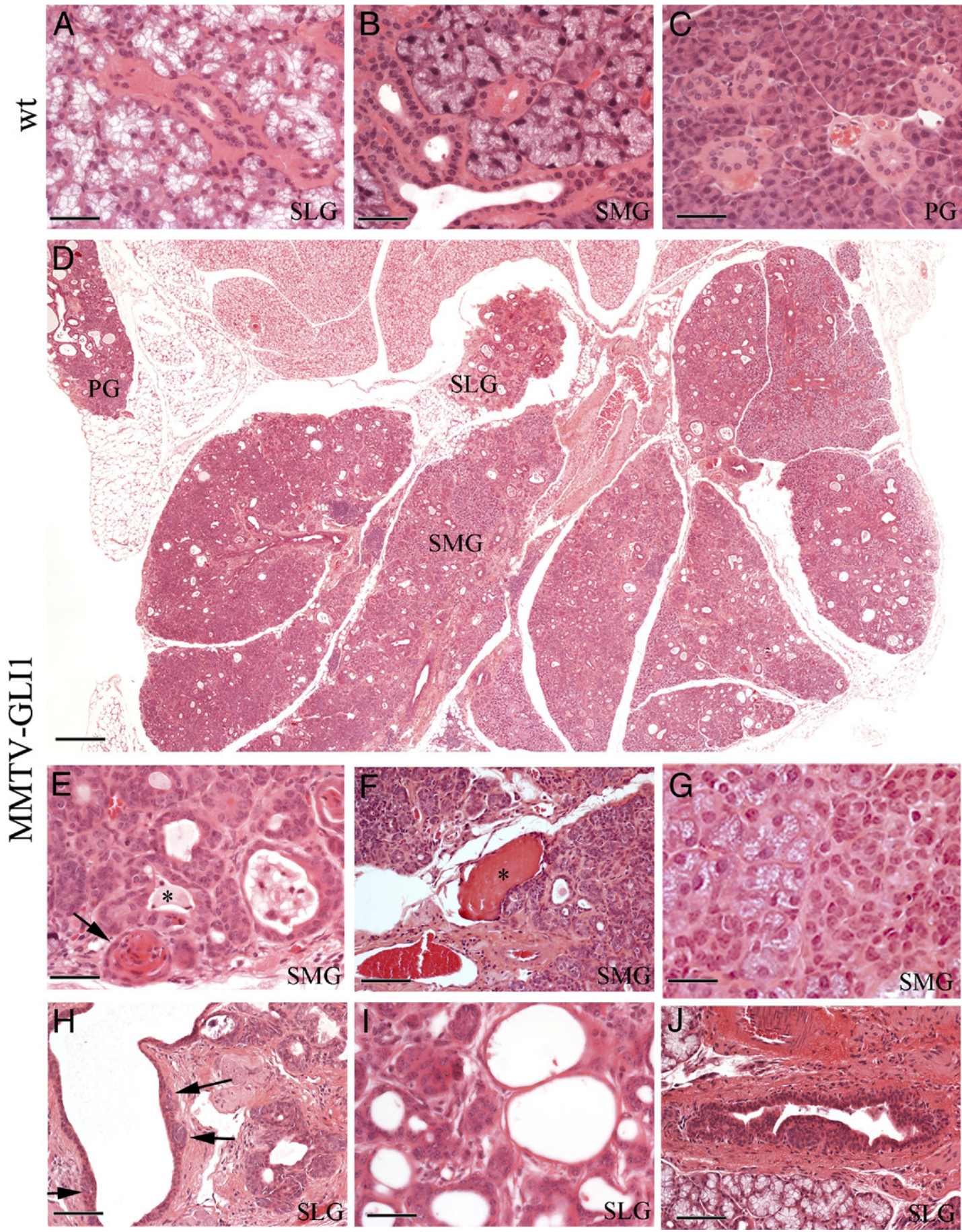

Figure 1. Salivary glands from MMTV-GLI1 mice display morphological defects. H\&E-stained sections from salivary glands isolated from wt (A-C) and transgenic GLI1 mice (D-J). The wt sublingual (SLG) (A), submandibular (SMG) (B) and parotid glands (PG) (C) show normal histological architecture whereas salivary glands removed from transgenic GLI1 mice, treated with doxycycline for 1 year, display histological defects (D and $\mathbf{H})$. Hyperplastic lesions appear as small aggregates of basaloid epithelial cells (D-J), preferentially peripheral to the duct luminal epithelial cells $[\mathbf{E}, \mathbf{H}$ (arrows), $\mathbf{I}, \mathbf{J}]$. Cystic ducts $(\mathbf{E}, \mathbf{H}$, and $\mathbf{I})$ with mucous luminal plugs $(\mathbf{E}$, asterisk) and metaplastic elements $(\mathbf{E}$, arrow) are also detected in GLI1 induced salivary glands. Prenatal activation of GLI1 expression results in an almost complete loss of normal SLG parenchyma already during first pregnancy (I) Postnatal activation of GLI1 in MMTV-GLI1 mice leads to a milder morphological phenotype in the SMG (G) and SLG (J). SMG from 1-year-old induced MMTV-GLI1 male mice reveals dense collagenous matrix deposition $(\mathbf{F}$, asterisk). Scale bars: $20 \mu \mathrm{m}(\mathbf{J}) ; 50 \mu \mathrm{m}(\mathbf{A}-\mathbf{C}, \mathbf{E}$, and $\mathbf{F}) ; 100 \mu \mathrm{m}(\mathbf{G}-\mathbf{I})$; and $500 \mu \mathrm{m}(\mathbf{D})$.

the PG epithelial cells were GLI1 positive in the MMTVGLI1-long-term salivary glands (Figure 3C). Because of the autoregulatory properties of the Hh signaling pathway, ${ }^{18}$ elevated expression of Ptch1; either mRNA or protein could be observed in response to GLI1 activation
(Figure 2, B and C). Furthermore, immunohistochemical stainings for GLI1 and Ptch1 on consecutive sections from MMTV-GLI1-long-term salivary glands revealed coexpression of GLI1 and Ptch1 (Figure 2D). In most GLI1expressing cells, Ptch1 expression appeared elevated 
A
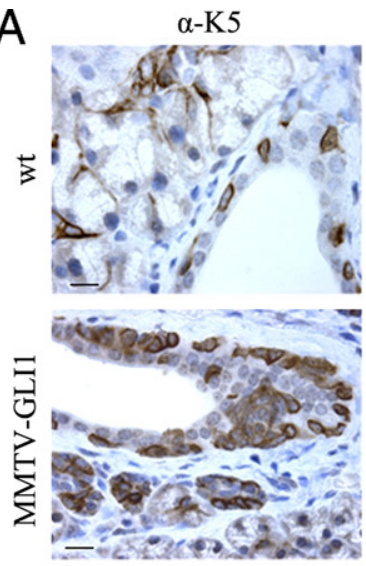

$\alpha-\mathrm{K} 6$
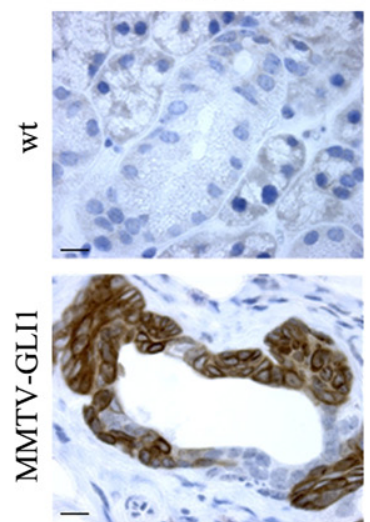

C MMTV-GLI1
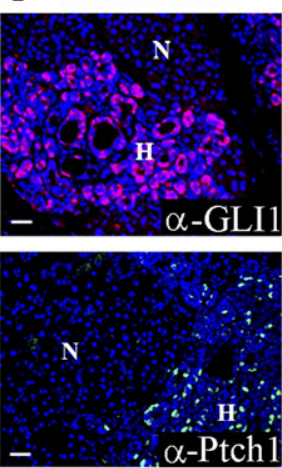

SMG

D
$\alpha-\mathrm{K} 14$
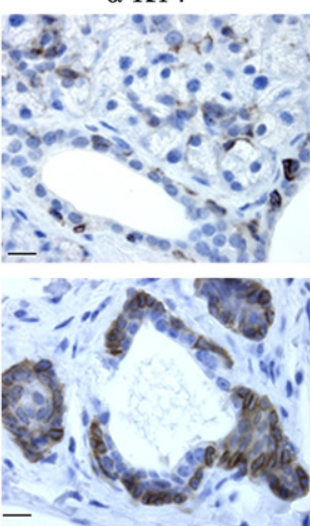

$\alpha-\mathrm{K} 8$
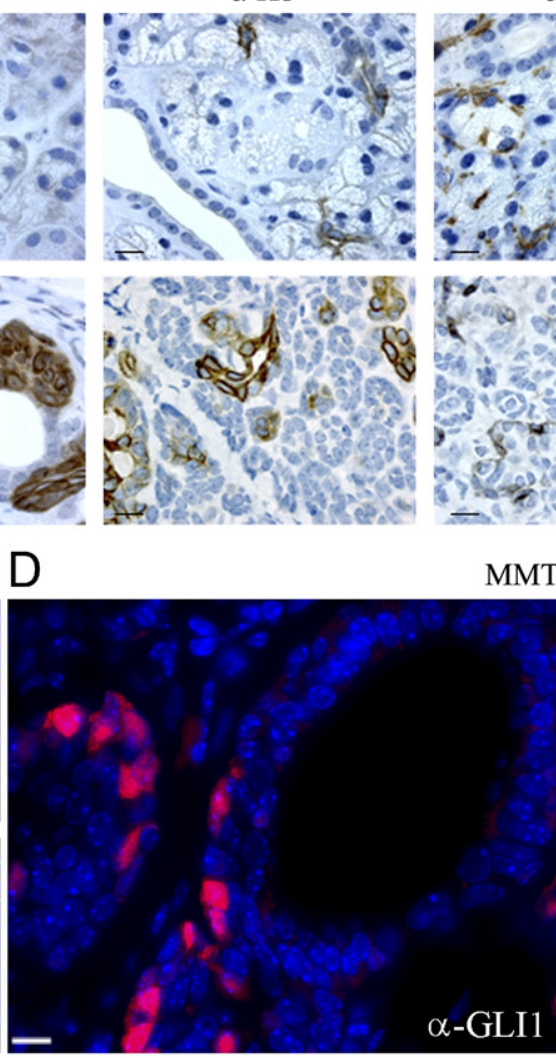

$\alpha-\mathrm{K} 17$

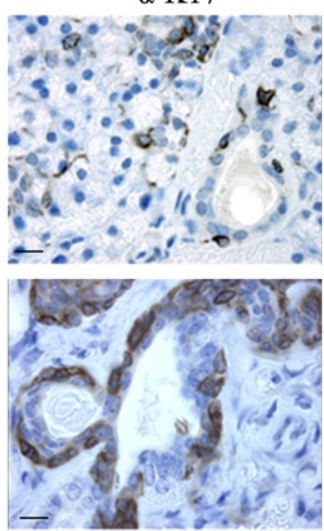

$\alpha$-SMA

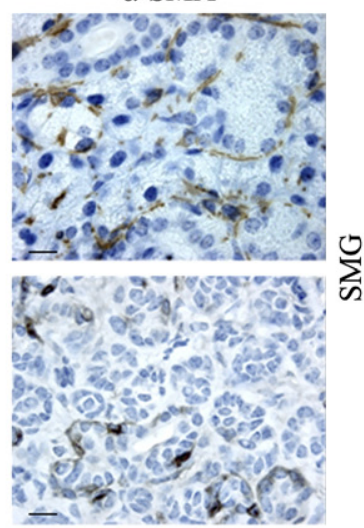

$\alpha-p 634$ A4

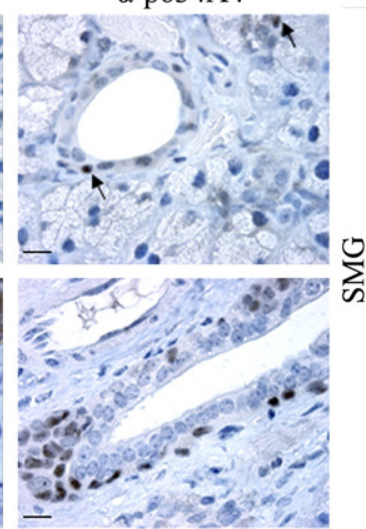

B

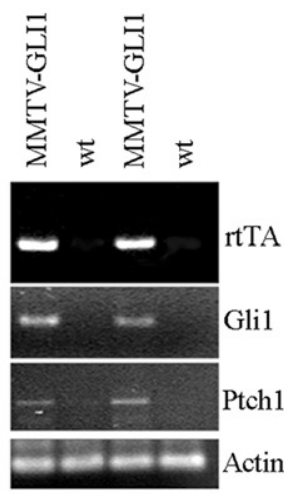

MMTV-GLI1

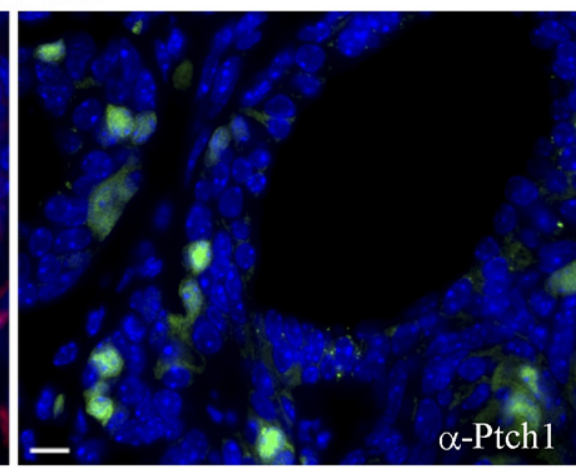

SMG

Figure 2. MMTV-GLI1 salivary glands strongly express GLI1 and present a wide range of epithelial markers. Immunostainings as labeled of submandibular gland (SMG) sections from wt and MMTV-GLI1 mice (A). Hyperplastic lesions preferentially arise as protrusions from the SMG ductal region and present high levels of expression of the basal epithelial markers K5, K14, K17, and p63 and low/absent expression of the luminal marker K8 and the myoepithelial marker SMA. Hyperplastic aggregates show intense K6 expression. RT-PCR analysis performed on total RNA extracted from GLI1 expressing bigenic and wt salivary glands reveal an increase in GLI1 and Ptch1 expression in transgene induced MMTV-GLI1 salivary glands (B). rtTA mRNA was only present in the bigenic mice and actin was used as a control. Immunofluorescence labeling of GLI1 and Ptch1 on sections from formalin fixed and paraffin embedded SMGs from 1-year-old parous MMTV-GLI1 mice (C). Nuclei were counterstained with Draq5. Histological normal SMG epithelial cells are marked with N, and hyperplastic changes are marked with H. Hyperplastic lesions show high expression of GLI1 and Ptch1, whereas histological normal epithelial cells do not. Immunohistological detection of GLI1 and Ptch1 on consecutive SMG sections from 1-year-old parous MMTV-GLI1 mice show co-expression of GLI1 and Ptch1 (D). Nuclei were counterstained with Draq5. Scale bars: $10 \mu \mathrm{m}(\mathbf{A}) ; 20 \mu \mathrm{m}(\mathbf{D}) ;$ and $30 \mu \mathrm{m}(\mathbf{C})$.

relative to adjacent GLI1-negative cells, consistent with pathway activation in GLI1-positive cells (Figure 2D). No alterations were ever observed in salivary glands taken from doxycycline-treated virgin bigenic (5-10 weeks), untreated bigenic, or doxycycline-treated wt animals (data not shown). Furthermore, only low/absent GLI1 and Ptch1 expression could be detected in control salivary glands when analyzed by RT-PCR (Figure 2B).

\section{GLI1 Induces Cell Proliferation and Cell Cycle Progression in the Salivary Gland}

Previously we described that mammary hyperplastic changes and tumors, arising as a result of ectopic GLI1 expression, showed an increased incorporation of BrdU and expression of Cyclin D1 and Snail. ${ }^{16} \mathrm{We}$ therefore set out to examine BrdU incorporation rates 
A
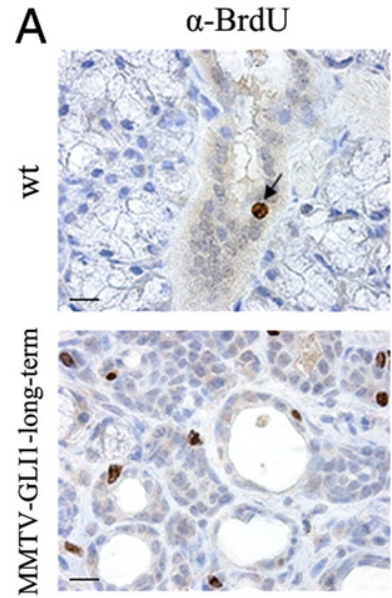

$\mathrm{B}$

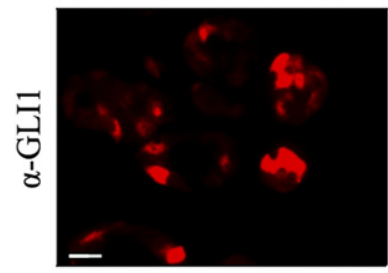

MMTV-GLI1-long-term

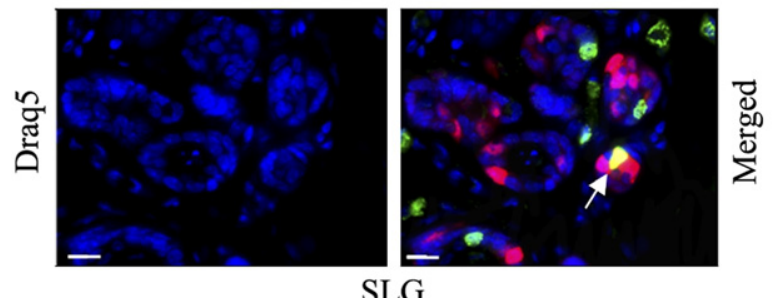

$\alpha-C y c l i n$ D1
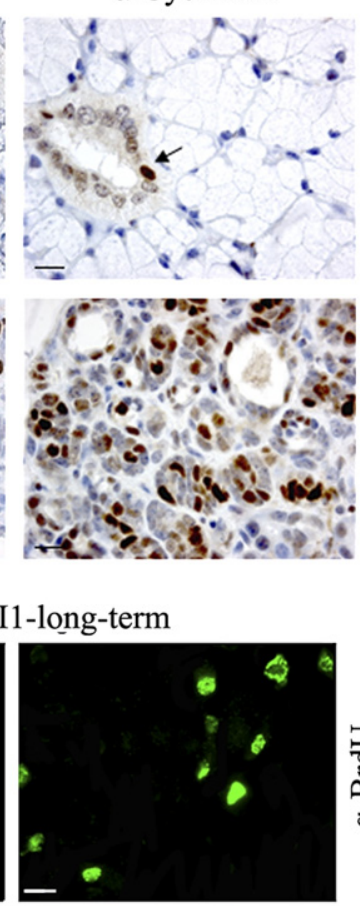

里

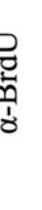

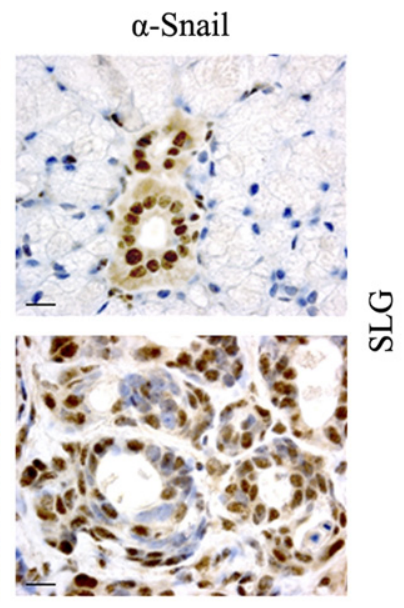

C

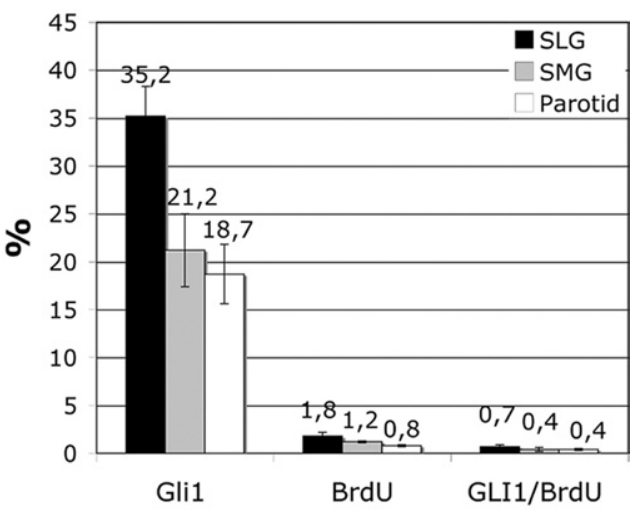

Figure 3. Targeted expression of GLI1 increase salivary gland proliferation. Immunohistological detection of BrdU incorporation and of Cyclin D1, and Snail protein expression in induced (doxycyclin treated for 1 year) bigenic and wt sublingual glands (SLG) (A). A marked increase of BrdU, Cyclin D1 and Snail labeled nuclei was observed in induced bigenic SLG epithelial cells when compared with cells in wt mice. Immunofluorescence labeling (B) and quantification (C) of GLI1, BrdU, and GLI1/BrdU double-positive cells in SLG with induced GLI1 expression (1 year). Nuclei were counterstained with Draq5. Arrow indicates GLI1/BrdU double-positive cell. Scale bars: $10 \mu \mathrm{m}(\mathbf{A}) ; 20 \mu \mathrm{m}$ (B).

and expression patterns of Cyclin D1 and Snail, in salivary glands of MMTV-GLI1-long-term parous females and wt control mice (Figure 3A). A high proportion of BrdU and Cyclin D1-positive cells were detected in the GLI1 expressing hyperplastic changes (Figure 3A). Immunofluorescence staining for BrdU incorporation revealed that $1.8 \% \pm 0.4 \%$ of SLG, $1.2 \% \pm$ $0.1 \%$ of $S M G$ and $0.8 \% \pm 0.1 \%$ of $P G$ epithelial cells in the MMTV-GLI1-long-term mice were BrdU positive (Figure 3, B and C). In addition, a large fraction of salivary epithelial cells in the GLI1 induced hyperplastic changes showed nuclear expression of Snail (Figure $3 \mathrm{~A}$ ). The observation that the bigenic expression of GLI1 was dramatically elevated (Figures 2C, 3B, and $3 \mathrm{C}$ ) in some but not all salivary epithelial cells led us to question to what degree transgene expression correlated with the proliferative status of the hyperplastic changes. Dual immunofluorescence staining for GLI1 and $\mathrm{BrdU}$ incorporation revealed that $0.7 \% \pm 0.2 \%$ of SLG, $0.4 \% \pm 0.2 \%$ of SMG and $0.4 \% \pm 0.1 \%$ of $P G$ epithelial cells in the MMTV-GLI1-long-term salivary glands were positive for both BrdU and GLI1 (Figure 3,
$B$ and $C$ ). These results indicate that a proportion of the GLI1 expressing cells are proliferating.

\section{Aberrant GL/1 Expression in the Salivary Glands Results in a Reduced Amount of Acinar Cells and an Altered Differentiation Program}

In contrast to normal SMGs, which mainly consists of densely packed secretory acini with widely spaced intercalated and striated ducts, histological analysis revealed a drastic loss of acini in the salivary glands with induced GLI1 expression (Figure 4, A-D). To determine whether the remaining acinar cells retained functional markers, the salivary glands were analyzed for the expression of Aquaporin 5 (AQP5) and $\mathrm{Na}-\mathrm{K}-\mathrm{Cl}$ co-transporter 1 [Nkcc1(Slc12a2)]. Although the GLI1 expressing salivary glands showed a dramatic reduction of AQP5 and Nkcc1 expressing acinar cells (Figure $4, \mathrm{~F}$ and $\mathrm{H}$ ), the localization of AQP5 to the apical membrane and Nkcc1 to the basolateral membrane was not altered in the few remaining MMTV-GLI1 acinar cells and did therefore not sug- 


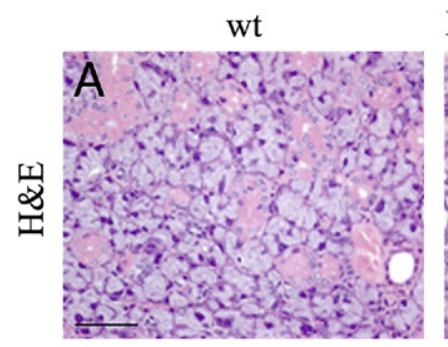

MMTV-GLI1-long-term
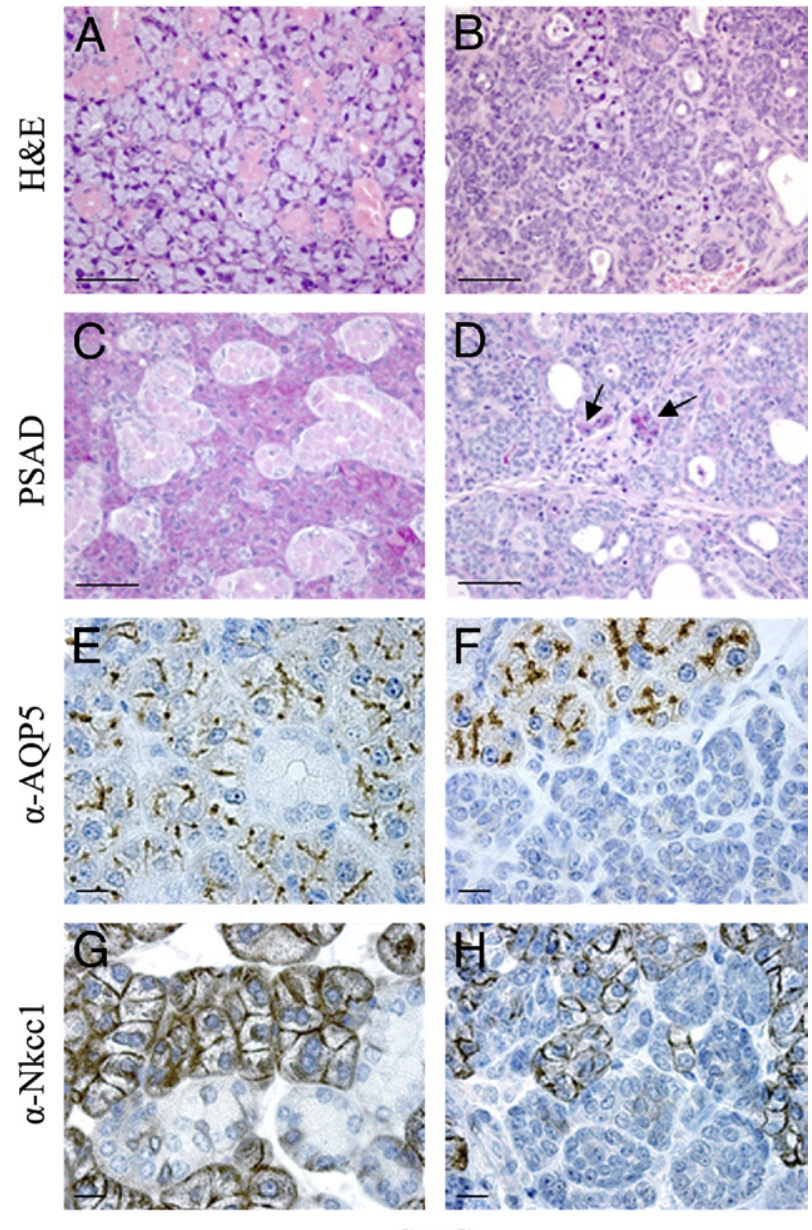

\section{SMG}

Figure 4. Forced GLI1 expression reduces salivary acinar differentiation. H\&E- and PASD-stained submandibular gland (SMG) sections show a dramatically reduced proportion of acinar structures in the long term (1 year) GLI1 expressing SMG (B and $\mathbf{D})$ when compared with wt (A, C). Immunohistological staining with anti-AQP5 (E and $\mathbf{F})$ and anti-Nkcc1 $(\mathbf{G}$ and $\mathbf{H})$ antibodies confirm the reduced amount of acinar structures in the long term (1 year) GLI1 expressing SMG (F and $\mathbf{H})$ as compared with wt (E and $\mathbf{G}$ ) AQP5 is expressed on the apical membrane of serous acinar cells, whereas Nkcc1 is expressed on the basolateral membrane of acinar cells and heterogeneously in ductal cells $(\mathbf{E}-\mathbf{H})$. Scale bars: $50 \mu \mathrm{m}(\mathbf{A}-\mathbf{D}) ; 10 \mu \mathrm{m}(\mathbf{E}-\mathbf{H})$.

gest any alteration of acinar cell function (Figure 4, E-H). Taken together, the low/absent expression of AQP5 and Nkcc1 in the MMTV-GLI1 salivary glands indicates that ectopic GLI1 expression leads to altered differentiation, resulting in fewer acinar cells (Figure 4, F and $\mathrm{H}$ ).

\section{GL11 Stimulates the Formation of Cystic Lesions in the Bigenic Salivary Glands}

In conjunction with the reduction of acinar structures in MMTV-GLI1 salivary glands, immunohistological analysis with the luminal epithelial marker $\mathrm{K} 8$ revealed a prominent increase in the proportion of ductal structures in all three major salivary glands (Figure 5 and data not shown). The increase in ductal structures was dramatic in prenatally induced MMTV-GLI1 mice analyzed at 6 to 19 weeks (Figure 5C) and at 1 year of age (Figure 5D), whereas MMTV-GLI1-3W mice sacrificed at 6 to 19 weeks of age (Figure 5B) displayed a smaller but clear increase as compared with wt mice (Figure 5A). In salivary glands from female MMTV-GLI1-prenatal mice, cystic lesions could be observed already during their first pregnancy (Figure 11). Cells in the expanded ducts showed a thinned and elongated appearance (see Supplemental Figure S3 at http://ajp.amjpathol.org). The lesions expressed the basal markers p63 and $\mathrm{K} 5$, and were positive for K6 and GLI1 (see Supplemental Figure S3 at http://ajp.amjpathol.org), whereas SMA was expressed to a very low extent (see Supplemental Figure S3 at $h t t p: / /$ ajp.amjpathol.org). Development of the ductal system in exocrine glands is dependent on cadherins for the establishment of epithelial polarity and proper cell-cell contact. ${ }^{19}$ To determine whether ectopic GLI1 expression affects ductal cell polarization, wt and GLI1 expressing salivary ducts were immunoassayed for E-cadherin. In addition to the normal localization to the cell-cell interface (see Supplemental Figure S4 at http://ajp.amjpathol.org), GLI1 induced hyperplastic changes showed high levels of E-cadherin on the epithelial cell-cell boarders (see Supplemental Figure S4 at $h$ ttp://ajp.amjpathol.org).

\section{GL11 Expression Induces Reversible Changes to the Salivary Gland Epithelium}

To determine whether the observed morphological alterations were maintained also after transgene inactivation, GLI1 expression was induced with doxycyclin supplementation from 3 weeks of age and continued for 12 to 15 weeks. Doxycycline was then removed from the drinking water and the mice were sacrificed 8 to 17 weeks later (Figure 6A). Compared with salivary glands from agematched GLI1 transgenic mice, which had been under constant doxycycline exposure [MMTV-GLI1 (+dox)], (Figure $6 C$ ), the MMTV-GLI1 (+dox, -dox) salivary glands contained more acinar structures, and reduced numbers of ducts and hyperplastic lesions (Figure 6B). Staining with the acinar cell markers AQP5 and Nkcc1 verified this normalization (Figure 6, B and C). Immunohistochemistry using a GLI1 antibody confirmed complete inactivation of the transgene following doxycyclin removal (data not shown).

\section{K5-GLI1 Mice Develop Histological Defects in the Major Salivary Glands}

In a previous publication we described skin changes in GLI1 transgenic mice in which expression was driven by the bovine keratin 5 promoter. ${ }^{15}$ Because $\mathrm{K} 5$ is also expressed in salivary myoepithelial and ductal basal cells, it was of interest to compare these mice with the MMTVGLI1 mice. As expected, similar morphological changes were seen in K5-GLI1 mice (Figure 7). This finding indicates that both promoters are active in similar, if not identical, cellular compartments, and it strengthens the notion that the changes that we observe develop from either myoepithelial or basal cells. Hyperplastic and squamous elements preferentially appeared in the salivary ducts (Figure 7A) and stained positive for basal 
wt

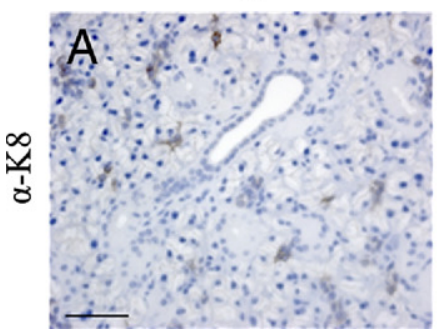

MMTV-GLI1-3w

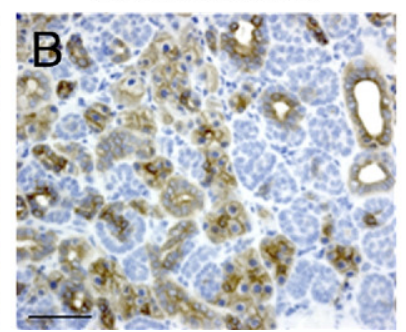

MMTV-GLI1-prenatal

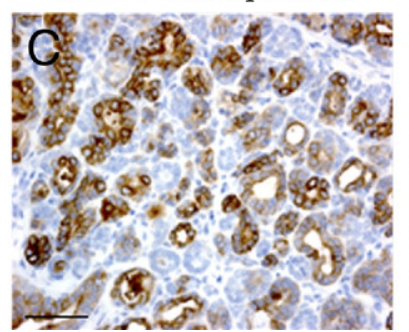

MMTV-GLI1-long-term

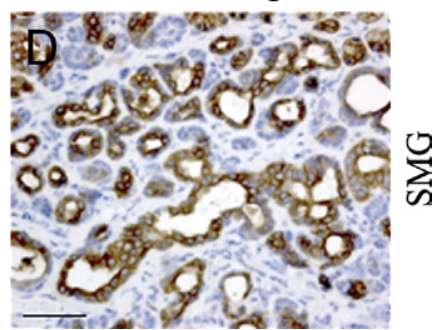

Figure 5. Aberrant GLI1 expression increases the number of ducts in the salivary glands. Immunohistological analysis with an anti-K8 antibody shows an increased amount of ductal structures in the GLI1 expressing submandibular gland (SMG) (B-D) as compared with wt (A). The increase in ductal structures was most prominent in prenatally induced mice (C) and in long-term doxycycline-treated mice (D). Mice exposed to doxycycline from 3 weeks of age also show an increase in SMG ductal structures after their first pregnancy (B). Scale bar, $50 \mu \mathrm{m}$.

markers (K5 and p63) and for K6 (Figure 7C). In contrast to the MMTV-GLI1 hyperplastic changes, which showed low/absent expression of K8 and SMA, K5-GLI1 changes displayed both $\mathrm{K} 8$ and SMA expression (Figure 7C). Of note, dual immunofluorescence labeling revealed no overlap between $\mathrm{K} 5$ and $\mathrm{K} 8$ expressing cells, whereas p63 and K6 showed co-expression (Figure 7C). RT-PCR (Figure 7B) and immunofluorescence labeling (Figure
7C) suggested that a high percentage of the salivary epithelial cells in the K5-GLI1 mice expressed GLI1, whereas no GLI1 expression was detected in salivary glands from wt mice (Figure 7B; see also Supplemental Figure S1 at http://ajp.amjpathol.org). Histological analysis also revealed changes in the preputial gland and in the thymus, all of which showed a strong resemblance to the hyperplastic lesions arising in the K5-GLI1 and

A

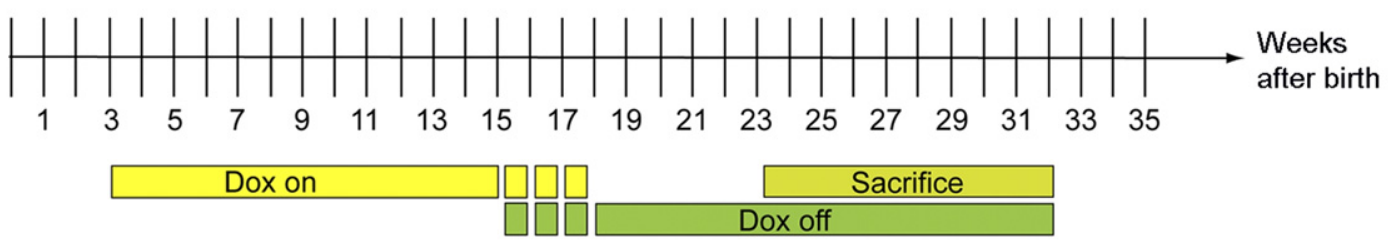

B
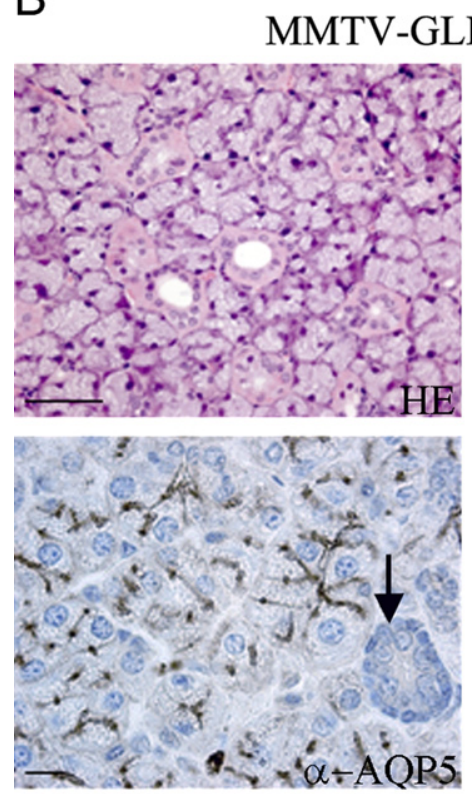

C
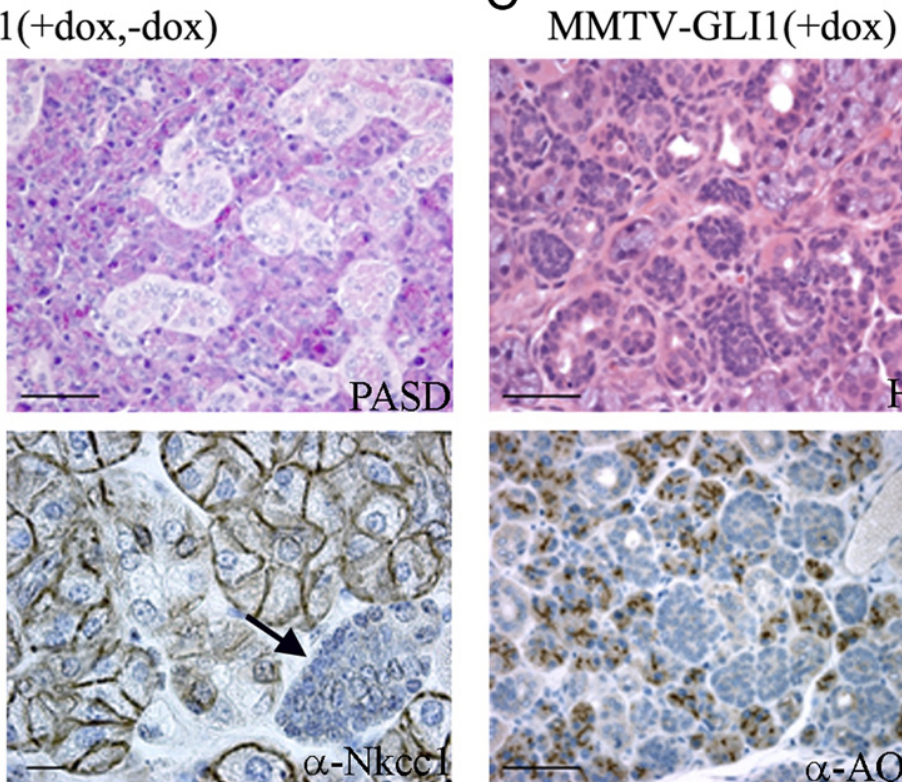

SMG
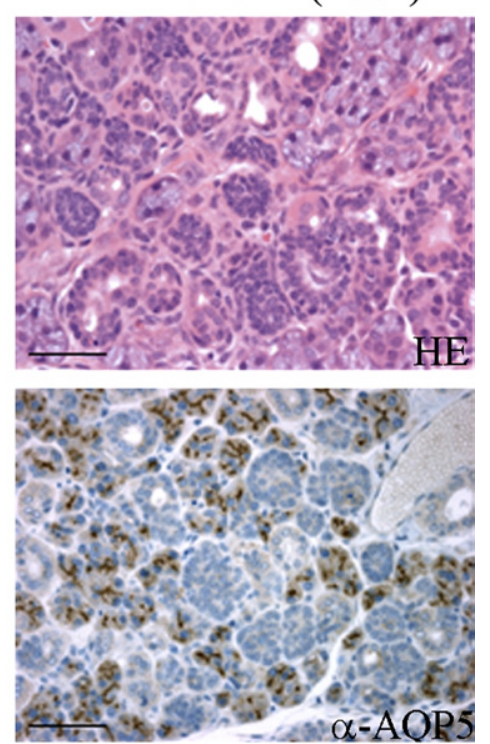

\section{SMG}

Figure 6. Maintenance of GLI1 induced salivary lesions is dependent on continous transgene expression. A: Experimental setup. Transgenic GLI1 mice were induced with doxycycline for 12 to 15 weeks, starting 3 weeks after birth, then taken off doxycyclin treatment and sacrificed 8 to 17 weeks later [MMTV-GLI1 (+dox, - dox)]. H\&E and PASD stainings of sections from MMTV-GLI1 ( + dox, - dox) submandibular glands (SMGs) show normalization, with an increase in acinar structures and reduction of cystic ducts and hyperplastic changes $(\mathbf{B})$. Immunostainings with anti-AQP5 and anti-Nkcc1 antibodies confirm the increase of acinar structures. Remaining hyperplastic lesions are marked with an arrow. C: Transgenic GLI1 mice, which have been under constant doxycycline exposure, starting 3 weeks after birth [MMTV-GLI1(+dox)], show a reduced number of acinar structures, increased numbers of ducts and hyperplastic lesions when compared with salivary glands removed from aged-matched MMTV-GLI1 (+dox, - dox) mice (B). Scale bars: $50 \mu \mathrm{m}$ [B (H\&E and PASD) and C]; $10 \mu \mathrm{m}$ [B ( $\alpha$-AQP5 and $\alpha$-Nkcc1)]. 
A
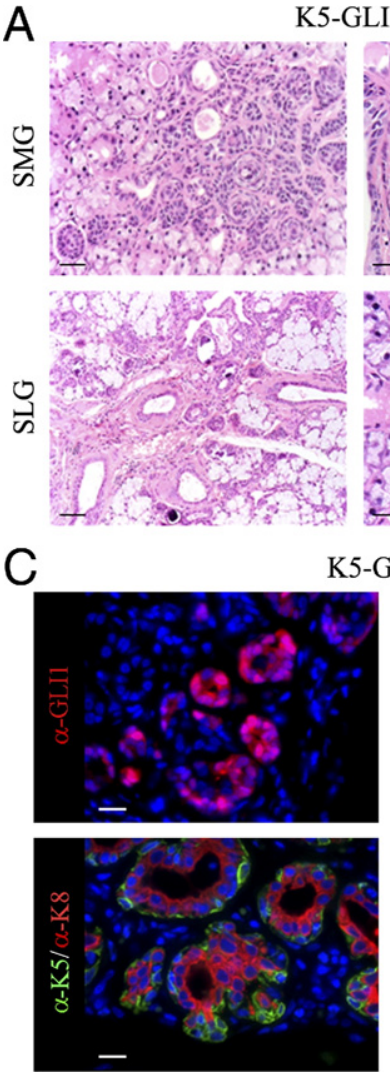

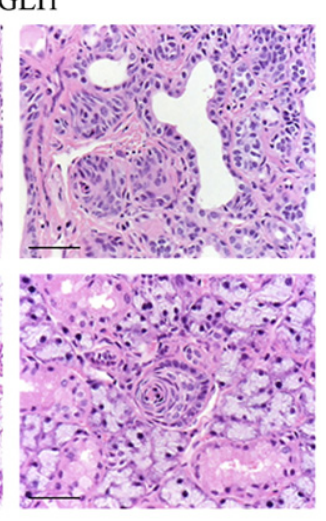

K5-GLI1
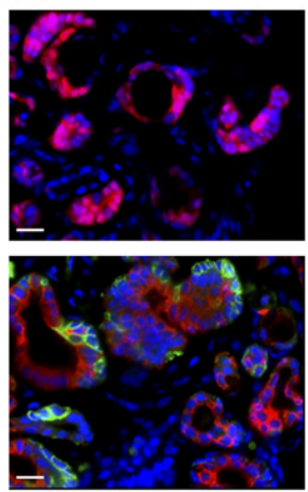

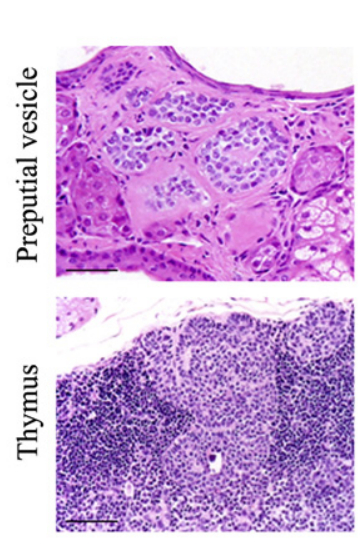

B
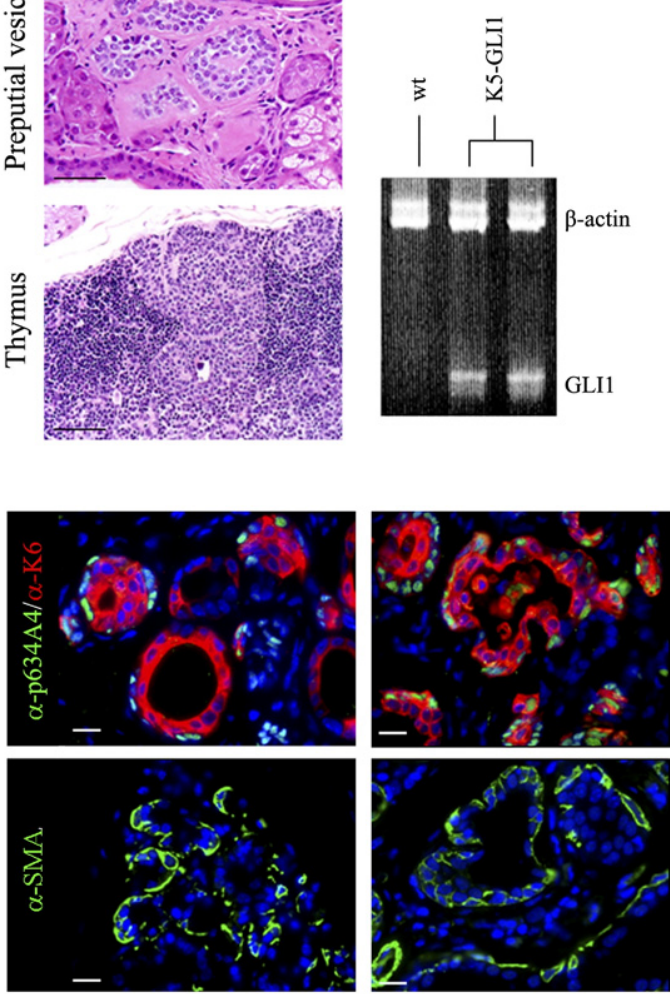

SMG

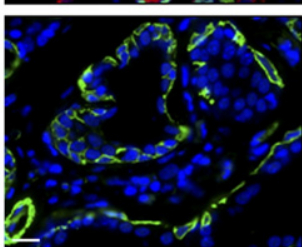

SLG

Figure 7. Mice ectopically expressing GLI1 under the K5 promoter present a wide range of morphological defects. A: Histological sections from nulliparous K5-GLI1 mice stained with H\&E showing morphological defects in the submandibular glands (SMG), sublingual glands (SLG), preputial gland and thymus. RT-PCR (B) and immunofluorescence labeling (C) demonstrate a high GLI1 content in the K5-GLI1 salivary glands. K5-GLI1 salivary glands show K5, K8, K6, p63, and SMA expression. Nuclei were counterstained with Draq5. Scale bars: $50 \mu \mathrm{m}(\mathbf{A}) ; 20 \mu \mathrm{m}(\mathbf{C})$

MMTV-GLI1 salivary glands (Figure 7A and Figure 1, D-J). Age-matched wt salivary glands showed normal expression of p63, K5, K8, SMA, and K6 (see Supplemental Figure S1 at http://ajp.amjpathol.org).

\section{Discussion}

The Hh signaling pathway plays a critical role during development, maintenance, and regeneration of a number of different organs. It is well established that inappropriate activation of the pathway can cause developmental defects and cancer. Although we are beginning to appreciate the importance of the Hh pathway in salivary gland development and maintenance, its specific role in histogenesis, homeostasis, and carcinogenesis is still poorly understood. To examine the consequences of aberrant $\mathrm{Hh}$ signaling in vivo, we transgenically expressed the Hh effector protein GLI1 in mouse salivary glands. We here show that an activated Hh signaling drastically changes the structure of all major salivary glands. GLI1 expressing salivary glands show increased proliferation together with hyperplastic and metaplastic lesions. Similar morphological defects appear regardless of when the pathway is activated, although to a varying extent. Thus, the morphological defects appear earlier and are more severe in salivary glands in which GLI1 expression is activated prenatally. Importantly, the GLI1 induced salivary gland changes are reversible on transgene inactivation, implying that these changes are dependent on continuous GLI1expression.

$\mathrm{Hh}$ signaling plays a key role during ductal and branching morphogenesis in several organs, including prostate $^{20}$ mammary gland ${ }^{21,22}$ and lung, ${ }^{23}$ and is known to influence the early formation of the mouse submandibular gland. ${ }^{6}$ In this context it is of interest that induced GLI1 expression resulted in an expansion of ductal structures, and a concomitant loss of acini, suggesting that the Hh pathway activation can induce salivary duct formation. The ducts are highly ordered structures, in which cell adhesion and polarization is in part maintained by E-cadherin and $\beta$-catenin. GLI1 expressing salivary glands show a slightly increased expression of E-cadherin at the cell-cell borders, which is in agreement with a previous study demonstrating that Shh promotes salivary cell polarization. ${ }^{8}$ GLI1 expressing ducts were more over found to be dilated, leading to a cystic appearance. This finding is supported by in vitro studies, in which Shh-supplemented salivary gland explants showed similar defects, ie, cystic lesions and increased lumen formation. 6,8

In addition to the expansion of ductal structures a decrease in the number of acini was observed in the GLI1 
expressing salivary glands, which was supported by the reduced expression of the acinar differentiation markers, AQP5 and Nkcc1. This strongly suggests that ectopic GLI1 expression in postnatal salivary glands, blocks acinar differentiation. In contrast, Shh-supplemented embryonic salivary explants showed that Hh activation promotes formation of acini-like structures prenatally. ${ }^{8}$ Similar markedly different roles of the Hh pathway during pre- and postnatal stages, has also been demonstrated, for example, in the prostate. ${ }^{20,24,25}$ Although expression analysis have suggested that $\mathrm{Hh}$ signaling, in developing salivary gland, acts within the epithelium in an autocrine/ juxtacrine manner, ${ }^{6}$ it is possible that $\mathrm{Hh}$ in addition acts via the surrounding stroma in a paracrine fashion. This could explain the differences seen when the pathway is activated by ligand supplement versus an effector molecule within the epithelial compartment.

The morphology of the GLI1 expressing salivary glands, with blocked acinar cell differentiation and ductal cell hyperplasia, show several similarities with the salivary gland morphology observed in patients who have undergone irradiation therapy or in mice where the terminal excretory duct has been ligated to prevent outflow of saliva. Ligation of the main excretory ducts is a method commonly used to induce salivary gland regeneration. The blockage results in induced proliferation of duct epithelial cells and expansion of the stem cell population. ${ }^{10}$ A recent study has shown that $\mathrm{Hh}$ signaling is indeed up-regulated in regenerating SMG following duct ligation. ${ }^{9}$ In this model, Hh activation was dependent on and downstream of Wnt, as forced activation of the Wnt pathway in salivary glands activates Hh, expands the stem/ progenitor cell population and promotes proliferation of ductal cells. ${ }^{9}$ Our finding that ectopic Hh pathway activation similarly results in increased proliferation and reduced acinar cell differentiation further strengthens the notion that $\mathrm{Hh}$ activation is sufficient to promote salivary gland regeneration. In line with this the Hh pathway has been implicated as a central player in tissue regeneration and repair in several other organs, by stimulating the proliferation and differentiation of stem/progenitor cells. ${ }^{26}$

Although the precise mechanism behind the formation of the morphological defects presented require further investigation, the results from our study altogether suggest that the targeted GLI1 expression promotes proliferation and restricts acinar cell differentiation of a stem/progenitor population. This is supported by the expanded cell population expressing K5, p63, and $\mathrm{K} 6$ and the observed increase in epithelial proliferation rate associated with an increase in Cyclin D1 expression. It is also of interest that the GLI1 induced hyperplastic lesions first appear in the proposed salivary stem cell compartment, the intercalated ducs (data not shown). ${ }^{27}$

Although dual immunofluorescence staining with GLI1 and cell cycle markers showed that GLI1-expressing salivary epithelial cells are indeed proliferative (Figure 3, B and $\mathrm{C}$ ), all proliferating cells do not express GLI1 [approximately $39 \%$ of SLG, $30 \%$ of SMG and $50 \%$ of PG BrdU positive epithelial cells showed GLI1 expression] (Figure 3C). A similar, non-cell-autonomous proliferative effect has previously been observed in mammary epithe- lial cells in mice expressing an activated human Smoothened (SmoM2) transgene. ${ }^{22}$ Although the reason for this effect is currently unclear, there are at least three plausible explanations. First, the simplest interpretation is that GLI1 is expressed and active in all BrdU-positive cells, but that GLI1 protein expression varies and is below detection limit in some cells. A second possibility is that the GLI1 protein is actively degraded and therefore cannot be detected in all BrdU positive cells. Finally, the GLI1 positive salivary epithelial cells may promote proliferation indirectly via an undefined paracrine/juxtacrine signaling factor(s).

In several of the tissues in which Hh is important for tissue renewal and repair, abnormal activation has been associated with tumorigenesis. In light of this and our previous observation that ectopic GLI1 expression induces tumors in both the skin ${ }^{15}$ and mammary gland, ${ }^{16}$ we postulated that aberrant GLI1 activation would lead to tumor formation also in the salivary glands. To date, we have not found any tumor formation in the GLI1-expressing salivary glands. The reason for this is unclear, but it is likely related to the level of transgene expression. Although analysis of the MMTV-rtTA line showed transgene induction in the salivary glands, expression was much higher in the mammary glands. ${ }^{28}$ Similarly, the bovine K5 promoter is more highly expressed in the basal cell layer of the epidermis as compared with the salivary glands. ${ }^{29}$

Although we have been unable to find any peer-reviewed publication of $\mathrm{Hh}$ involvement in formation of salivary gland tumors, there have been a few reports favoring such a role. The development of tumors resembling the aggressive human salivary duct carcinoma in $\mathrm{K} 5$-cre activated Gli2-overexpressing mice has been described in a congress abstract ${ }^{30}$ and the identification of GLI2 genomic amplification in human oral basaloid squamous cell carcinomas suggested the involvement of GLI2 in this tumor subtype. ${ }^{31}$ Because basal cell adenomas/adenocarcinomas seem to preferentially develop in salivary glands but are also found in other internal organs, it is tempting to speculate that $\mathrm{Hh}$ signaling components are involved in the development of these tumors. The changes we find in the MMTV-GLI1 mice may therefore represent one end of the spectrum in the development of these tumors. However, further investigation of human salivary basal cell tumors is needed to establish such a relationship.

\section{Acknowledgments}

The use of animal facilities within the Clinical Research Center, Karolinska University Hospital is gratefully acknowledged. The authors thank Åsa Bergström for technical support.

\section{References}

1. Tucker AS: Salivary gland development. Semin Cell Dev Biol 2007, 18:237-244

2. Jaskoll T, Melnick M: Embryonic Salivary Gland Branching Morphogenesis. In Branching Morphogenesis (Molecular Biology Intelligence Unit) Edited by Davies J. Landes Bioscience/Eurekah.com, Georg- 
town, TX and Springer Science + Business Media, New York, NY, pp $160-175$

3. Patel VN, Rebustini IT, Hoffman MP: Salivary gland branching morphogenesis. Differentiation 2006, 74:349-364

4. Jaskoll T, Zhou YM, Chai Y, Makarenkova HP, Collinson JM, West JD, Hajihosseini MK, Lee J, Melnick M: Embryonic submandibular gland morphogenesis: stage-specific protein localization of FGFs. BMPs, Pax6 and Pax9 in normal mice and abnormal SMG phenotypes in FgfR2-IIIc(+/Delta), BMP7(-/-) and Pax6(-/-) mice. Cells Tissues Organs 2002, 170:83-98

5. Chuong CM, Patel N, Lin J, Jung HS, Widelitz RB: Sonic hedgehog signaling pathway in vertebrate epithelial appendage morphogenesis: perspectives in development and evolution. Cell Mol Life Sci 2000, $57: 1672-1681$

6. Jaskoll T, Leo T, Witcher D, Ormestad M, Astorga J, Bringas P, Jr., Carlsson P, Melnick M: Sonic hedgehog signaling plays an essential role during embryonic salivary gland epithelial branching morphogenesis. Dev Dyn 2004, 229:722-732

7. Chiang C, Litingtung Y, Lee E, Young KE, Corden JL, Westphal H, Beachy PA: Cyclopia and defective axial patterning in mice lacking Sonic hedgehog gene function. Nature 1996, 383:407-413

8. Hashizume A, Hieda Y: Hedgehog peptide promotes cell polarization and lumen formation in developing mouse submandibular gland. Biochem Biophys Res Commun 2006, 339:996-1000

9. Hai B, Yang Z, Millar SE, Choi YS, Taketo MM, Nagy A, Liu F: Wnt/beta-catenin signaling regulates postnatal development and regeneration of the salivary gland. Stem Cells Dev 2010, 19:1793-1801

10. Hisatomi Y, Okumura K, Nakamura K, Matsumoto S, Satoh A, Nagano $\mathrm{K}$, Yamamoto T, Endo F: Flow cytometric isolation of endodermal progenitors from mouse salivary gland differentiate into hepatic and pancreatic lineages. Hepatology 2004, 39:667-675

11. Fendrich V, Esni F, Garay MV, Feldmann G, Habbe N, Jensen JN, Dor $Y$, Stoffers D, Jensen J, Leach SD, Maitra A: Hedgehog signaling is required for effective regeneration of exocrine pancreas. Gastroenterology 2008, 135:621-631

12. Kang DH, Han ME, Song MH, Lee YS, Kim EH, Kim HJ, Kim GH, Kim DH, Yoon S, Baek SY, Kim BS, Kim JB, Oh SO: The role of hedgehog signaling during gastric regeneration. J Gastroenterol 2009, 44:372379

13. Hennighausen L, Wall RJ, Tillmann U, Li M, Furth PA: Conditional gene expression in secretory tissues and skin of transgenic mice using the MMTV-LTR and the tetracycline responsive system. J Cell Biochem 1995, 59:463-472

14. Fiaschi M, Rozell B, Bergstrom A, Toftgard R, Kleman MI: Targeted expression of GLI1 in the mammary gland disrupts pregnancy-induced maturation and causes lactation failure. J Biol Chem 2007, 282:36090-36101

15. Nilsson M, Unden AB, Krause D, Malmqwist U, Raza K, Zaphiropoulos PG, Toftgard R: Induction of basal cell carcinomas and trichoepitheliomas in mice overexpressing GLI-1. Proc Natl Acad Sci USA 2000, 97:3438-3443

16. Fiaschi M, Rozell B, Bergstrom A, Toftgard R: Development of mammary tumors by conditional expression of GLI1. Cancer Res 2009, 69:4810-4817

17. Li G, Robinson GW, Lesche R, Martinez-Diaz H, Jiang Z, Rozengurt $\mathrm{N}$, Wagner KU, Wu DC, Lane TF, Liu X, Hennighausen L, Wu H:
Conditional loss of PTEN leads to precocious development and neoplasia in the mammary gland. Development 2002, 129:41594170

18. Agren M, Kogerman P, Kleman MI, Wessling M, Toftgard R: Expression of the PTCH1 tumor suppressor gene is regulated by alternative promoters and a single functional Gli-binding site. Gene 2004, 330: 101-114

19. Hogan BL, Kolodziej PA: Organogenesis: molecular mechanisms of tubulogenesis. Nat Rev Genet 2002, 3:513-523

20. Lamm ML, Catbagan WS, Laciak RJ, Barnett DH, Hebner CM, Gaffield W, Walterhouse D, lannaccone P, Bushman W: Sonic hedgehog activates mesenchymal Gli1 expression during prostate ductal bud formation. Dev Biol 2002, 249:349-366

21. Moraes RC, Chang H, Harrington N, Landua JD, Prigge JT, Lane TF, Wainwright BJ, Hamel PA, Lewis MT: Ptch1 is required locally for mammary gland morphogenesis and systemically for ductal elongation. Development 2009, 136:1423-1432

22. Moraes RC, Zhang X, Harrington N, Fung JY, Wu MF, Hilsenbeck SG, Allred DC, Lewis MT: Constitutive activation of smoothened (SMO) in mammary glands of transgenic mice leads to increased proliferation, altered differentiation and ductal dysplasia. Development 2007, 134: $1231-1242$

23. Urase $\mathrm{K}$, Mukasa $\mathrm{T}$, Igarashi $\mathrm{H}$, Ishii $\mathrm{Y}$, Yasugi $\mathrm{S}$, Momoi MY, Momoi $\mathrm{T}$ : Spatial expression of sonic hedgehog in the lung epithelium during branching morphogenesis. Biochem Biophys Res Commun 1996 225:161-166

24. Podlasek CA, Barnett DH, Clemens JQ, Bak PM, Bushman W: Prostate development requires sonic hedgehog expressed by the urogenital sinus epithelium. Dev Biol 1999, 209:28-39

25. Wang BE, Shou J, Ross S, Koeppen H, De Sauvage FJ, Gao WQ: Inhibition of epithelial ductal branching in the prostate by sonic hedgehog is indirectly mediated by stromal cells. J Biol Chem 2003 , 278:18506-18513

26. Jiang J, Hui CC: Hedgehog signaling in development and cancer. Dev Cell 2008, 15:801-812

27. Man YG, Ball WD, Marchetti L, Hand AR: Contributions of intercalated duct cells to the normal parenchyma of submandibular glands of adult rats. Anat Rec 2001, 263:202-214

28. Gunther EJ, Belka GK, Wertheim GB, Wang J, Hartman JL, Boxer RB, Chodosh LA: A novel doxycycline-inducible system for the transgenic analysis of mammary gland biology. FASEB J 2002, 16:283-292

29. Ramirez A, Bravo A, Jorcano JL, Vidal M: Sequences 5' of the bovine keratin 5 gene direct tissue- and cell-type-specific expression of a lacZ gene in the adult and during development. Differentiation 1994 58:53-64

30. Ermilov A, Brown J, Roessler E, Wang A, Liu J, Grachtchouk M, Silva ND, Ramirez A, Jorcano J, Muenke M, Dlugosz AA: 137. Constitutive hedgehog signaling activity, via GLI2 expression, is sufficient for salivary gland tumorigenesis. The 67th Annual Meeting of the Society for Investigative Dermatology, May 3-6, 2006, Philadelphia, PA. J Investig Dermatol 2006, 126:S1

31. Snijders AM, Schmidt BL, Fridlyand J, Dekker N, Pinkel D, Jordan RC Albertson DG: Rare amplicons implicate frequent deregulation of cell fate specification pathways in oral squamous cell carcinoma. Oncogene 2005, 24:4232-4242 